УДК 81 '27

DOI: 10.33184/YVDK-2021-04-30.29

И.Ю. Моисеева (проф. ОГУ, г. Оренбург),

О.И. Антипова (магистрант, ОГУ, г. Оренбург)

\title{
АНАЛИЗ ЛИНГВИСТИЧЕСКОГО КОМПОНЕНТА ЯПОНСКОЙ КУЛЬТУРЫ НА ПРИМЕРЕ СТИЛЯ ОБЩЕНИЯ В ЯПОНИИ
}

В статье проводится анализ лингвистического компонента японской культуры на примере стиля общения в Японии. Вылдлена невербальная и вербальная коммуникация. K особенностям невербального общения в Японии относится отношение $к$ молчанию, способу передачи информации без разговора. К особенностям вербального отношения относятся деления на «своих» $u$ «чужих», тактики общения между работниками в офисе, а также психологические проблемы общения между людьми. Анализ проводится на примере лингвистических компонентов японского языка, невербальной и вербальной коммуникации на конкретные примеры из диссертационных работ и статей, а также на примерах японского кинематографа и японской анимащии, и японских комиксов.

Ключевые слова: японская культура, лингвистический компонент культуры, невербальная коммуникация, вербальная коммуникачия, стили общения, «свои» и «чужсие».

The article analyzes the linguistic component of Japanese culture on the example of the communication style in Japan. Highlighted non-verbal and verbal communication. One of the peculiarities of non-verbal communication in Japan is the attitude towards silence, a way of transmitting information without speaking. The peculiarities of the verbal attitude include the division into "us" and "strangers", tactics of communication between employees in the office, as well as psychological problems of communication between people. The analysis is carried out using the example of the linguistic 
components of the Japanese language, non-verbal and verbal communication for specific examples from dissertations and articles, as well as examples of Japanese cinema and Japanese animation, and Japanese comics.

Key words: Japanese culture, linguistic component of culture, non-verbal communication, verbal communication, communication styles, "ours" and "others".

При изучении любой страны всегда встает вопрос не только о языке, но и о её культуре. Культура в широком смысле, трактуется Т.В. Жеребило как «все, что создано человеческим обществом, благодаря физическому и умственному труду людей, в отличие от явлений природы. В более узком смысле: идейное и нравственное состояние общества, определяемое материальными условиями жизни общества и выражаемое в его быте, идеологии, образовании и воспитании, в достижениях науки, искусства, литературы» [Жеребило 2010].

И разумеется, у каждой страны своя особенная культура, сложившаяся за долгие годы. В нашей статье мы сделаем акцент на культуру Японии.

Е.Л. Катасонова, анализируя культуру Японию, подчеркивает, что она берет свое начало с переселения предков современных японцев на архипелаг с материка, а также со становления культуры периода Дзёмон. В последствии, в виду полной изоляции страны (политика сакоку) в период правления сёгуната Токугавы, культура стала идти по уникальному пути, создавая свои собственные ценности, которые могут шокировать любого жителя других стран. Однако современная культура Японии испытала сильное влияние Азии, Северной Америки и Европы, в особенности после проигрыша во Второй Мировой войне [Катасонова 2012].

Культура сама по себе является объединением многих компонентов, каждый из которых заслуживает отдельного рассмотрения: фольклор, живопись, музыка, язык и многое другое.

Целью данной статьи является анализ лингвистического компонента, его структуры и особенности на примере речи современных японцев, а также примерного вида общения и того 
влияния, которое подобный вид общения вносит в цельную культуру Японии, как компонент.

Материалом статьи послужили:

1) диссертационные исследования и статьи в области культурологии, философии и лингвистики за период с 2010 по 2021 год на сайтах CYBERLENINKA и eLibrary.Ru;

2) аниме «Хоримия» («ホリミヤ», режиссер Исихама Масаси, «Как сложно любить отаку» («ヨタクに恋は難しい», режиссер Хирайкэ Ёсимаса), фильмы «Бродяга Кенсин» («るろうに剣心», режиссер Кэйдзи Отомо), «После сезона цветов» (《花のあと», режиссер Наканиси Кэндзи), а также вебновелла «Повторная жизнь» («リライフ», автор Яёй Со).

Под лингвистическим компонентом мы понимаем знания, вовлекаемые в процесс обучения учебному предмету: языковой материал (лексический, грамматический, фонетический), речевой, социокультурный [Багрова 2012].

В лингвистический компонент культуры входит вербальное и невербальное общение.

По определению, А. Мирошниченко, «невербальная коммуникация - это общение, обмен информацией без помощи слов. Это жесты, мимика, различные сигнальные и знаковые системы. Все эти способы общения по аналогии иногда также называют языками - первичными и вторичными, или естественными и искусственным» [Мирошниченко 2008] .

По словам О.Р. Лихолетовой в её работе «Концепт «間 Ма» и способы его репрезентации в японском языке», в японской культуре большое значение придают молчанию и тишине. Для них молчание может иметь не меньший вес и передавать информацию, как и речь. При помощи паузы или тишине собеседник передает искренность и особую значимость уже сказанного, позволяя другому собеседнику обдумать и сделать свои выводы, в отличие от западной культуры, в котором молчание является признаком неловкости и её необходимо избегать. Японцы же своим молчанием оказывают уважение собеседнику, достигая его понимая непрямым или невербальным общением. Однако подобное относится не только к «чужакам» в общении, но и к своей семье. Тем не менее, внутри своей семьи не возбраняется общаться больше, чем того требует этикет, и это 
не считается зазорным [Лихолетова 2019]. Стоит отметить, что в культуре у японцев не принято показывать явно свои эмоции. Зачастую раньше тот, кто проявил эмоции, показывал душу. Если при этом учитывать их веру в то, что все одушевленно, то открывать душу было чревато последствиями - душу мог захватить ёкай (демонический или злобный дух) или как-то проклясть. Впоследствии это вошло в норму и привычку, вошло в этикет общения. Сложно встретить активного, шумного и несдержанного японца. Для них в порядке вещей сохранять сдержанность, спокойствие внешне, даже если внутри себя в них будут бушевать эмоции. Это можно заметить так же во многих воспоминаниях людей, общающихся с японцами или же даже в фильмах, демонстрирующих показательную сдержанность и хладнокровие. Таким образом, невербальное общение зачастую куда более информативно, чем вербальное.

Вербальная коммуникация, в свою очередь, по определению из словаря С.М. Вишнякова, это «процесс общения с помощью языка, т. е. речь. Под речью здесь понимается естественный звуковой язык, который является универсальным средством коммуникации, поскольку при передаче информации с его помощью менее всего теряется смысл общения». [Вишнякова 1999]

В Японии речь сдержанная, спокойная, порой даже без эмоциональная. Однако японцы не всегда сдержаны и без эмоциональны, придерживаясь культуры молчания и тишины. Все дело в том, что они четко разграничивают общение, создавая так называемые «круги общения» друг с другом. Для японцев, по словам М.Н Корнилова, существует деление на «своих» и «чужих», или же ути (内) и сото (外). Своими считаются люди, которые имеют одинаковое мышление и ценности (семья), когда как «чужаки» - все остальные [Корнилов 2005].

В работе В.А. Пронникова и И.Д. Ладанова «Япония: этнопсихологические очерки» так же подчеркивается, что японцам с детства прививают способы общения, которые делится на внешний и внутренний. Однако, даже скрываясь за внешним спокойствием, японцы могут угадать истинные чувства человека по некоторым характерным признакам. Именно такое деление они называют татэмаэ-хоннэ. Внешнее лицо (татэмаэ) является 
маской, за которой скрывается истина. Однако, как уже говорилось выше, старшее поколение может различать за внешней «маской» истинные чувства человека. Для них скрывать эмоции за «маской» не лицемерие - это скорее норма, принятая в обществе, чтобы оставаться вежливым по отношению к другим [Пронников, Ладанов 1985]. В работе Н.Н. Изотовой «Этнокультурные особенности стиля японской коммуникации» подчеркивается, что такая особенность появилась вследствие замкнутости общения. Многие японцы на протяжении столетий жили в одном и том же месте, не покидая и не переезжая никуда из своего родного дома. И потому между членами общины развивались близкие отношения настолько, что они могли понять друг друга по едва заметным жестами или изменениям в мимике [Изотова 2012].

Тем не менее, если возвращаться к работе М.Н. Корнилова, такие нормы общения могут повлечь за собой психологические проблемы. Например, «тайдзинкё: фусё:», которое переводится как «антропофобия». Этот синдром характеризуется боязнью общения, стресса в присутствии людей, а также покраснениями, заиканиями и т.д. В основном от такой болезни страдают мужчины и юноши от четырнадцати лет, что является следствием преувеличением японских ценностей. Например, в Японии прямой контакт глазами (за исключением членов семьи или близких друзей) считается неприемлемым [Корнилов 2005]. Зачастую люди, страдающие антрофобией в Японии, как рассматривает Е. Кузнецова, стараются ограничить себя от общения максимально, превращаясь в субкультуру хикикомори (яп. 引きこもり, букв. «нахождение в уединении»). Такие люди максимально ограничивают себя в общении, социализации, и зачастую находятся на иждивении родственников. Единицы из них могут одновременно с этим удаленно работать. Однако те из японцев, кто не желает мириться с этим, проходит курс реабилитации, и, как показывает опыт, в дальнейшем практически полностью излечиваются [Кузнецова 2020].

Возможно, на способ именно такого общения в кругу семьи повлияла система «家 иэ». Одно из значений этого слова «семейная линия, род». В статье Ю.С. Дейко «К вопросу о 
репрезентации природно-климатических и культурных ценностей японского народа в языке» говорится о том, что система «Иэ» является формой патриархата, в котором глава семьи обладает абсолютной властью и несет ответственность за каждого члена своей семьи. Именно поэтому главе семьи, самому пожилому человеку, оказывали всяческое почтение. Самурайское «иэ» отличалось от крестьянского - самураи старались прославить свой род или же упрочнить влияние, которое они распространяли. На своих территориях они имели власть, позволяющую решать вопросы бракосочетания, развода и усыновления. Таким образом, внутри семьи решались многие важные вопросы, тогда как при внешнем общении оставались либо итоги, либо же все скрывалось. Если можно выразится русской поговоркой, то японцы «не выносят сор из избы», чтобы не тревожить общественность. И хотя система «иэ» была аннулировано после Второй Мировой войны, она повлекла за собой значительные изменения в системе коммуникации всего японского сообщества [Дейко 2013].

В свою очередь внешнее общение, зачастую с коллегами или просто знакомыми людьми, характеризуется побудительными или же подобными стилями общения. В работе С.В. Чиронова «Ещё раз о японской коммуникации: типичные речевые тактики японцев в побудительном контексте» объясняются тактики общения, в котором говорящий объясняет свою мысль адресату путем нескольких тактик. Например, ссылка на существующие правила и нормы (narubeku), возникающая при ситуации, когда говорящий владеет информацией, которая, в свою очередь, не известна адресату. Таким образом подобная побудительная тактика становится наставительной, показывая не только запрет или действие, но и способы выполнения. Поэтому дистанция здесь между говорящим и адресатом довольна большая. Чего нельзя сказать о другой тактике, «zehi», при которой дистанция между говорящим намного меньше. В этом случае собеседник побуждает его послушать, потому что предлагаемое действие несет в себе пользу или выгоду для слушающего. Так же, при помощи такой тактики общения можно нейтрализовать возражения, показывая, как легко и просто совершить действие или же просто попытаться, надеясь на то, что 
тогда адресат сам согласится на выполнение этого действия [Чиронов 2017].

Перейдем к анализу невербального и вербального общения на примере практического материала.

1. Невербальное общение.

Как уже говорилось выше, для японцев характерно вставлять паузы в общении, чтобы донести свою мысль и придать ей вес. Примером подобного невербального общения в фильме «Бродяга Кенсин» служит момент, когда Сайто Хадзимэ, глава полиции, разговаривает с Кенсином о том, чего он добьется, оставаясь бродягой и отказываясь от пути меча. Кенсин молчит, но это служит ответом, что он не бросит свой путь отказа от насилия и крови, несмотря на все слова, сказанные ему бывшим врагом. Он продолжает идти вперед, и его молчание в этот момент сильнее любых слов [Бродяга Кенсин 2012].

Так же примером невербального общения может служить фильм «После сезона цветов». На самом деле каждый момент пропитан молчанием и неспешностью, где движение, мимика и молчание говорят больше о действиях, чем слова. Конкретный пример - главная героиня никогда прямо не озвучила свои чувства, но её взгляд, манера речи и действия говорят о её чувствах больше, чем какие-либо слова. В конце фильма, когда госпожа Ито подходит поприветствовать своего жениха, в её взгляде видна благодарность за помощь, которую Сайсукэ оказал ей. Но она не произносит слова благодарности в слух, лишь кивает глубоко, и мужчина понимает без слов то, что сказала ему девушка. Он не задает дополнительных вопросов, просто принимая благодарность и беспокоясь о состоянии своей невесты [После сезона цветов 2010].

2. Вербальное общение.

Если говорить об отношениях внутри семьи или с близкими друзьями, то японцы могут кардинально меняться, показывая скрытые черты. Отношения и скрываемость за масками демонстрируются в популярном аниме ホリミヤ (Хоримия). Главный герой Миямура, по всем показателям в школе скрытый и нелюдимый подросток, в то время как Хори популярная и красивая девушка. Их дружба начинается с того, что они увидели «других» себя - то, что Хори в свободное время 
вынуждена быть домохозяйкой из-за занятости родителей и следить за братом, а Миямура - выглядит как бунтарь-подросток с пирсингом. Они начинают доверять друг другу, и вскоре «маски», которые они надевают перед окружающими, становятся не нужны. Так, в первой же серии взаимодействие между героями ограничивается несколькими фразами, демонстрирующими вежливое отношение между незнакомцами:

«- Хори-сан?

- Что? (в аниме произносится как «え», это можно перевести и как междометие «а» и как уточнение вопроса)

- Ты телефон обронила. (Здесь Миямура немного замедляет речь, показывая себя, как замкнутого человека, однако речь лишена любого эмоционального подтекста)

- А, спасибо. (Хори так же отвечает без эмоционально, показывая небольшое безразличие, в отличие от недавнего разговора с друзьями)».

Спустя некоторое время, когда они стали общаться чаще и ближе, Хори осознает, что не знает имени Миямуры (её мама говорит, что странно, что она не знает имени своего друга, что подчеркивает значение, при котором друзья называют друг друга именно по имени). Уже в середине второй серии она признается в этом, отчего Миямура рассмеялся: «- Мое имя?! Ты из-за этого так сильно переживала?! Мое имя? Имя?»

Её братик так же решает немного посмеяться над сестрой:

«- Сестрица - убогая! Убогая!» - мальчик использует слово «おねえーちゃん», которую обычно используют близкие родственники, родные братья или сестры.

Хори резко парирует:

«И как я должна была спросить об этом?!», показывая, что при дружбе уже неприлично спрашивать имя, так как подразумевается, что вы его уже знаете. Тон разговора уже не столь равнодушный, а намного более эмоциональный, показывающий взаимоотношения двух друзей, а не просто одноклассников. К тому же, в этом же моменте Миямура показывает, что сам знает имя Хори, так как уже считал её своим другом. Таким образом их разговоры так же из официального и вежливого, но равнодушного тона меняются на 
более простые и более эмоциональные, но понятные слова, доносящие прямой контекст. [Хоримия 2021]

В это же время нельзя сказать, что во всех местах поощряется говорить сразу напрямую. В некоторых фирмах наоборот, не приветствуется увлечение чем-либо и отход от официального тона общения для поддержания общего командного духа. Примером подобного общения может служить аниме «Как сложно любить отаку», где с самой первой серии заметна разница общения главных героев в офисе и вне его: в офисе Наруми Момосэ обращается к другу детства, используя вежливые приставки, такую как -кун, «-君». Однако спустя некоторое время она, сидя с ним же в баре, обращается уже без приставок, что показывает уровень близости с ним, как с другом. Обращаться к кому-то без вежливой приставки в Японии считается очень грубым, только если вы не являетесь близки к друг другу. Так же из жизнерадостного и наигранного своего образа Наруми показывает, что на самом деле чувствует, когда ей пришлось покинуть предыдущую компанию, а также причину, по которой пришлось это сделать. Они ведут разговор друг друга о личных отношениях, и Наруми спрашивает:

«- А? Как это (тут Наруми говорит «え? 何?», что дословно можно перевести как «А? Что?»)? У тебя что, появилась девушка?»

Вести разговор о личной жизни в Японии даже между друзьями считается не вежливым или даже неприличным. Но Хиротака спокойно отвечает на вопрос, что показывает уровень доверия и близости между ними. Уже в этой серии, когда они в офисе и общаются между собой, то снова обращаются друг к другу вежливо, не раскрывая общих тем для разговора и обращаясь только по теме работы. Примечательно так же то, что межличностные отношения на работе в Японии неприемлемы, что подчеркивается на протяжении всех серий. [Как сложно любить отаку 2018]

Тем не менее, так же имеются негативные стороны разграничения общения, которые ведут за собой психологические проблемы. В веб-новелле «Повторная жизнь» рассказываются различные истории, главной мыслью которых является то, что герои не смогли правильно выразить свои мысли или же 
попросить психологической помощи. Чидзуру Хисиро из-за постоянных переездов уверена, что отношения с людьми дружеские или романтические - лишь помеха, так как это не самое важное. И тем самым она не может прижиться ни в одной компании и ни на одной работе. Это наглядно продемонстрировано в одной из арок данной работы, в которой Хисиро, самовольно распределив роли для каждого, сама же желает выполнить работу. Однако дело не в взаимопомощи - она твердо уверена, что все другие только испортят общую работу, а она единственная, кто сможет выполнить её правильно и быстро. Но в конце арки с подготовкой к мероприятию она осознает свою ошибку и старается её исправить вместе с друзьями. В то же время есть момент из жизни Араты Кайзаки о своей наставнице и коллеге, которая умерла из-за давления со стороны коллектива. В его воспоминаниях коллега и наставница говорит о том, что она пыталась быть лучшей со всеми. Однако, из-за стремления стать лучше, её коллеги «стали воспринимать её не как соперницу, но как врага». Вследствие чего и началась травля, из-за которой женщина и погибла, не сумев выдержать давления. Но самым ярким примером является Оога Такаоми, брат одного из второстепенных персонажей. Юноша работал всю свою юность, чтобы помочь семье, никогда не открывал своих переживаний и старался быть поддержкой. Однако именно поэтому в семье не заметили, что его начали травить на работе и в повседневной жизни, после чего юноша замкнулся и прекратил общение с кемлибо, даже со своей семьей. Он стал хикикомори, решив дистанцироваться от внешнего мира, который разрушил его психику. Это наглядно показывается в главе «6-168 Признание». В день, когда он принял это решение, его брат зашел в комнату и увидел сообщение, которое Такаоми писал сам себе, состоящее из одного слова, повторяющегося много раз, «Сдохни». Затем, когда брат хотел остановить его, то Такаоми не выдержал и выгнал его из комнаты, вышвырнув и свой телефон. После этого, осознав, он через дверь стал извиняться, путая слова, не в силах объяснить проблему. Однако брат все понял, только прочитал сообщения на телефоне Такаоми [Повторная жизнь 2013].

Подводя итоги анализа лингвистического компонента, мы приходим к выводу о том, насколько различается способы общения японцев и какую роль в этом играет культура самой 
страны. Основным отличием является особенность невербальное общение, проявляющееся путем молчаливых пауз в речи и невыразительной мимике. Как было показано выше, оно более информативно и весомо для японца, нежели сама речь. Вербальное общение характеризуется делением на «своих» и «чужих», и это различие наиболее заметно, чем в других странах, особенно европейских.

\section{ЛИТЕРАТУРА:}

1. Багрова А.Я. Основные компоненты содержания обучения иностранному языку в общеобразовательной школе // Вестник Московской международной академии, 2012, №1. [Электронный ресурс]. URL: https:/cyberleninka.ru/article/n/osnovnye-komponenty-soderzhaniya-obucheniyainostrannomu-yazyku-v-obscheobrazovatelnoy-shkole (дата обращения: 11.04.2021).

2. Бродяга Кенсин (《るろうに剣心»). Художественный фильм, режиссер Кэйдзи Отомо, 2012 год.

3. Вишняккова С.М. Профессиональнюе образование: Словарь. Ключевые понятия, термины, актуальная лексика.-М::НМЦСПО, 1999. - 538 с.

4. Дейко Ю.С. К вопросу орепрезентацииприродно-климатических условий и культурных ценностей японского народа в языке // Известия вузов. СевероКавказский регион. Серия: Общественные науки, 2013, №4 (176). [Электронный pecypc]. URL: hitps:/cyberleninkaru/article/n/k-voprosu-oreprezentatsii-prirodno-klimaticheskih-usloviy-i-kulturnyh-tsennostey-yaponskogonaroda-v-yazyke (дата обращения: 18.04.2021).

5. Жеребило Т.В. Словарь лингвистических терминов. - Назрань: ООО «Пилигрим», 2010.- Изд. 5-е, испр. и доп.-486с.

6. Изотова Н.Н. Влияние норм традиционной японской морали на формирование конщепта «Счастье» // Вестник МГИМО, 2011, №3. [Электронный ресурc]. URL: https:/cyberleninkaru/article/n/vliyanie-normtraditsionnoy-yaponskoy-morali-na-formirovanie-kontsepta-schastie (дата обращения: 10.04.2021).

7. Изотова Н.Н. Этнокультурные особенности стиля японской коммуникации // Вестник МГИМО, 2012, №6. [Электронный ресурс]. URL: https:/cyberleninka.ru/article/n/etnokulturnye-osobennosti-stilya-yaponskoykommunikatsii (дата обращения: 16.04.2021).

8. Как сложно любить отаку («ヨタクに恋は難しい»). Аниме, режиссер ХирайкэЁсимаса, 2018 год. 
9. Катасонова Е.Л. Японцы в реальном и виртуальном мирах: очерки современной японской массовой культуры. - М.: Восточная литература, 2012. $-357 \mathrm{c}$.

10. Корнилов М. Н. Японская культурная традиция: коммуникационный и психопатологический подходы // Социальные и гуманитарные науки. Отечественная и зарубежная литература. Сер. 9, Востоковедение и африканистика: Реферативный журнал, 2005, №3. [Электронный ресурс]. URL: $\quad$ https:/cyberleninkaru/article/n/2005-03-052-053-yaponskaya-kulturnayatraditsiya-kommunikatsionnyy-i-psihopatologicheskiy-podhody (дата обращения: 15.04.2021).

11. Кэммоку А., Кузнецова Е. Безвыходное положение // Вокруг света, 2020, №6 (2957). [Электронный ресурс]. https:/www.vokrugsveta.ru/article/336224/(дата обращения: 13.04.2021).

12. Лихолетова О.Р. Концепт «間ма» и способы его репрезентации в японском языке// Филологическиенауки в МГИМО, 2019, №3(19). - С. 92-99.

13. Мирошниченко А.А. Бизнес-коммуникации. Мастерство делового общения. Практическое руководство. -М.: «Книжный мир», 2008. -384 с.

14. Повторная жизнь («リライフ»). Веб-новелла, автор Яёй Сo, 2013 год.

15. После сезона цветов (《花のあと»). Художественный фильм, режиссер НаканисиКэндзи, 2010год.

16. Пронников В.А., Ладанов И.Д. Японцы (этнопсихологическиеочерки). - М.: Главная редакция восточной литературы издательства «Наука», 1985. - 348 c.

17. Хоримия(«ホリミヤ»). Аниме, режиссер Исихама Масаси, 2021 год.

18. Чиронов С.В. Ещё раз о японской коммуникации: типичные речевые тактики японцев в побудительном контексте// Японскиеисследования. 2017. №1. [Электронный ресурc]. URL: https://cyberleninka.ru/article/n/eschyo-raz-oyaponskoy-kommunikatsii-tipichnye-rechevye-taktiki-yapontsev-v-pobuditelnomkontekste. (дата обращения: 09.04.2021).

(С Моисеева И.Ю., Антипова О.И., 2021 г. 